a chiropractors bill on the statute book as soon as possible. But, I would argue, this does not necessarily imply that all other complementary treatments should follow, or that the medical profession should support their bids for formal recognition.

Three criteria ought to be applied in reaching a decision on whether recognition and regulation are appropriate. Firstly, the treatment should rest on solid foundations in science and in examinable knowledge and skills. Secondly, objective proof should exist that it cures or alleviates pain and suffering when practised skilfully and that it has the potential for harm in the wrong hands. And, lastly, a substantial public demand should exist for the treatment and the public should need expert help to differentiate safe from unsafe practice. Of course, these criteria can be challenged and refined. What matters is that there should be some clarity in determining which treatments ought to follow along the path now marked out by the osteopaths.

One other matter highlighted by the Osteopaths Bill is that there may well be a need to reform the act governing the professions supplementary to medicine. Physiotherapists, for example, seem to believe that the present Council for the Professions Supplementary to Medicine is not working well and that it is unfair that osteopaths should now be achieving clearer recognition and more straightforward self governance than they themselves enjoy. Many doctors will sympathise with them. The barrier to reform seems to be mainly one of obtaining scarce parliamentary time for the amendment of primary legislation. That cannot be done with a private member's bill. Such reform would have to receive government priority in competition with all the other matters on which British governments always seem anxious to legislate.

ROBERT J MAXWELL Secretary

The King's Fund,

London W2 4HT

\title{
The chronic fatigue syndrome: what do we know?
}

\section{That it's a complex interaction of cerebral dysfunction, trigger factors, and social attitudes}

Abnormally persistent or recurrent fatigue is a feature of many disorders. Recently, particular attention has been devoted to people whose life is dominated by protracted and disabling fatigue. Such cases are now usually categorised as the chronic fatigue syndrome, the postviral fatigue syndrome, or myalgic encephalomyelitis. Two recent publications bring together current ideas on the topic. ${ }^{12}$

The historical background is important. Although the chronic fatigue syndrome has been advanced as a malaise of the latter part of this century, such cases are not a new phenomenon: they were particularly common during the latter part of the last century. ${ }^{3}$ The New York physician George Beard applied the label "neurasthenia" to them although the term was more widely used. After becoming an exceedingly common diagnosis it waned at the time of the first world war.

This first wave in the history of chronic fatigue was followed by a second wave, which can be dated to $1934 .^{3}$ Nevertheless, cases of chronic fatigue did not simply disappear in the intervening period. The "effort syndrome" had a considerable vogue at that time. "Fibrositis," a term introduced by Sir William Gowers in 1894 to designate the occurrence of diffuse muscle aching and pain without detectable explanation, evolved into "fibromyalgia." This currently popular diagnosis has many overlapping features with the chronic fatigue syndrome, ${ }^{4}$ as did the effort syndrome. ${ }^{5}$

In 1934 a large outbreak of a paralytic illness occurred among the staff of Los Angeles County General Hospital. Several similar outbreaks subsequently occurred, which came to be referred to as "epidemic neuromyasthenia." One such outbreak, which was to have an important influence on the course of events, took place at the Royal Free Hospital, London, in 1955. Little doubt exists that this was an epidemic of mass conversion hysteria, ${ }^{7}$ possibly triggered by a small nucleus of cases of postinfective encephalomyelitis. The term "benign myalgic encephalomyelitis," later abbreviated to myalgic encephalomyelitis (ME), was applied to this epidemic. Such outbreaks have to be distinguished quite firmly from the isolated cases that are now encountered. ${ }^{8}$ Some of the patients affected in the acute outbreak at the Royal Free Hospital continued to have recurrent fatiguability and muscle pain, and sporadic patients with these symptoms that occurred later were then labelled as having myalgic encephalomyelitis.

The clinical manifestations, although dominated by severe fatigue (precipitated even by slight effort) and by myalgia after exercise, encompass many other symptoms, including cognitive, emotional, and multisystemic symptoms. Because of the diffuse and changing descriptions given in different reports, attempts have been made to draw up precise, specific criteria for the diagnosis. ${ }^{9}$ The chronic fatigue syndrome seems the most acceptable label. Myalgic encephalomyelitis is not. Myalgia is certainly a feature, but there is no evidence for encephalomyelitis. Although the illness can be triggered by a viral infection, this is not true for all patients, and the frequently used term "postviral fatigue syndrome" is best avoided.

The prominence of fatiguability and muscle pain led many to conclude that the chronic fatigue syndrome is a muscle disorder. The careful physiological studies of Richard Edwards ${ }^{10}$ and others have firmly established that patients have central subjective fatigue and not a myopathic disorder. The muscle pain after exercise represents the phenomenon of damage to muscle fibres occurring during eccentric contraction in people who are persistently physically inactive. ${ }^{11}$

The cause of the chronic fatigue syndrome remains a highly contentious and emotive issue. It is imperative to identify neurological diseases producing similar symptoms. Most neurologists will have encountered patients with conditions such as primary sleep disorder, hypothyroidism, the LambertEaton myasthenic syndrome, early multiple sclerosis, or even frontal tumours in whom the chronic fatigue syndrome has been diagnosed. Some conditions, such as mitochondrial myopathies, may require sophisticated investigations for their exclusion. But such cases with an underlying neurological disorder are rare. In most cases it is an inescapable conclusion 
that a psychiatric disorder is involved: this was true for three quarters of the cases reported in the series of Wessely and Powell ${ }^{12}$ and Mann et al..$^{13}$ Depression was the commonest diagnosis, with anxiety and somatisation disorder being less frequent. It has been suggested that depression may be a secondary phenomenon. ${ }^{14}$ One important feature that distinguishes patients with the chronic fatigue syndrome from other patients with depression is that they are less likely to report feelings of guilt, unworthiness, and self blame. ${ }^{15}$

Strenuous efforts have been made to identify a nonpsychiatric explanation, the main proposals having been chronic infection with Epstein-Barr or Coxsackie virus. Immune activation has also been reported. ${ }^{16}$ Apart from acute viral infections acting as a trigger, no unequivocal evidence exists for persistent viral infection. Selecting appropriate control subjects has been a problem in studies.

The search for a "physical" cause outside the patient highlights the current unfortunate attitudes towards psychiatric illness, recalling the social stigma attached to tuberculosis or epilepsy in former generations. It also emphasises the regrettable and entirely inappropriate practice of doctors of distinguishing between "organic" and "non-organic" disorders, with the implication that non-organic disorders have no physical basis or even that the symptoms are purely in the mind. The fatigue that patients with the chronic fatigue syndrome experience is an exceedingly discomforting symptom and must have a neural correlate. So far the physiology of subjective central fatigue is largely unexplored, but investigations into the mechanism of objective central fatigue have been initiated. ${ }^{17}$

Fatigue is present in many patients with depression. It is also common in Parkinson's disease, when it correlates better with coexistent depression than with the severity of disease but is often independent of both. ${ }^{18}$ Interestingly, nearly a quarter of patients in the series reported by Wessely and Powell ${ }^{12}$ had no other features of depression or psychiatric disorder. Persistent subjective fatigue may therefore occur in relative isolation, independently of other manifestations of affective disorder. Some progress is being made with the functional imaging of depression by positron emission tomography, ${ }^{19}$ and advances in technology could conceivably allow exploration of the anatomical basis of subjective fatigue.

Subjective fatigue is, of course, a normal phenomenon. Possibly the setting of the neural mechanisms responsible for this sensation is altered in patients with the chronic fatigue syndrome and depression, in the same way that in anorexia nervosa the body image may be altered. Gibson et al have shown that the degree of perceived exertion is significantly greater in relation to the increase in heart rate during incremental exercise in patients with the chronic fatigue syndrome compared with normal subjects. ${ }^{20}$ This abnormal perception of effort was originally identified by Lloyd et al. ${ }^{21}$

The chronic fatigue syndrome reflects a complex interaction between cerebral dysfunction, trigger factors, and social attitudes and is complicated by secondary symptoms. There will be no simple explanation.

PKTHOMAS

Royal Free Hospital School of Medicine, Emeritus professor of neurology

London NW3 2PF

1 Bock GR, Whelan J, eds. Chronic fatigue syndrome. Chichester: John Wiley, 1993. (Ciba Foundation symposium 173.)

2 Dawson DM, Sabin TD, eds. Chronic fatigue syndrome. Boston: Little, Brown, 1993.

3 Shorter E. Chronic fatigue in historical perspective. In: Bock GR, Whelan J, eds. Chronic fatigue syndrome. Chichester: John Wiley, 1993:6-22. (Ciba Foundation symposium 173.)

4 Goldenberg DL, Simms RW, Geiger A, Komaroff AL. High frequency of fibromyalgia in patients with chronic fatigue seen in primary care practice. Arthritis Rheum 1990;33:381-9.

5 Wood P. Da Costa's syndrome (or effort syndrome). $B M \mathcal{F} 1941$ : i: 767-72.

6 Poskanzer DC, Henderson DA, Kunkle DA, Kalter SS, Clement WB, Bond JO. Epidemic neuromyasthenia: an outbreak in Punta Gorda, Florida. NEngl F Med 1957;257:356-64.

McEvedy CP, Beard AW. Royal Free epidemic of 1955: a reconsideration. BM7 1970;i:7-9.

8 Wessely S, Thomas PK. The chronic fatigue syndrome-myalgic encephalomyelitis or postviral fatigue. In: Kennard C, ed. Recent advances in clinical neurology. Edinburgh: Churchill fatigue. In: Kennard C,

9 Holmes GP, Kaplan JE, Gantz NM, Komaroff AL, Schonberger LB, Straus SE et al. Chronic fatigue syndrome: a working case definition. Ann Intem Med 1988;108:387-9.

10 Edwards RHT, Gibson H, Clague JE, Halliwell T. Muscle histopathology and physiology in chronic fatigue syndrome. In: Bock GR, Whelan J, eds. Chronic fatigue syndrome. Chichester: John Wiley, 1993:102-31. (Ciba Foundation symposium 173.)

11 Edwards RHT. Muscle fatigue and pain. Acta Med Scand 1986; (suppl 711):179-88.

12 Wessely S, Powell R. Fatigue syndromes: a comparison of chronic 'postviral' fatigue with neuromuscular and affective disorders. F Neurol Neurosurg Psychiatry 1989;42:940-8.

13 Mann P, Lane TJ, Matthews DA. Chronic fatigue and chronic fatigue syndrome: clinical epidemiology and aetiological classification. In: Bock GR, Whelan J, eds. Chronic fatigue syndrome. Chichester: John Wiley, 1993:23-42. (Ciba Foundation symposium 173.)

14 Rogers MP, Chang G. Psychiatric aspects. In: Dawson DM, Sabin TD, eds. Chronic fatigue syndrome. Boston: Little, Brown, 1993:45-68.

15 Powell $R$, Dolan $R$, Wessely $S$. Attributions of self-esteem in depression and chronic fatigue syndromes. F Psychosom Res 1990;34:665-73.

16 Landay AL, Jessop C, Lenette ET, Levy JA. Chronic fatigue syndrgme: clinical condition associated with immune activation. Lancet 1991;34:665-73.

17 Brasil-Neto JP, Pascual-Leone A, Valls-Solé J, Cammarota A, Cohen LG, Hallett M. Post-exercise depression of motor evoked potentials: a measure of central nervous system fatigue [abstract] Neurology 1993;43:A421.

18 Friedman JH, Friedman H. Fatigue in Parkinson's disease [abstract]. Neurology 1993;43:A237-8.

19 Bench CJ, Friston KJ, Brown RG, Scott LC, Frackowiak RSJ, Dolan RJ. The anatomy of melancholia-focal abnormalities of cerebral blood flow in major depression. Psychol Med 1992;22:607-16

20 Gibson H, Carroll N, Clague JE, Edwards RHT. Exercise performance and fatiguability with chronic fatigue syndrome. I Neurol Neurosurg Psychiatry (in press.)

21 Lloyd AR, Hales JR, Gandevia SC. Muscle strength, endurance and recovery in the post-infection fatigue syndrome. I Neurol Neurosurg Psychiatry 1988;51:1316-22.

\title{
Screening for cystic fibrosis in primary care
}

\author{
Family practice at last?
}

A new harmless compound detects carriers of cystic fibrosis by turning their urine blue. When it is taken orally by carrier couples at conception gametes with the cystic fibrosis gene will be inactivated. Cystic fibrosis can be eradicated.

It is not true, of course. Detection of carriers is elaborate; there are over 200 possible mutations, and testing for the more common faults in the gene misses one in six carriers. Even with complete uptake of the test, almost one third of affected fetuses would still reach term. 'In addition, avoidance of an affected child requires a termination. Before becoming enmeshed in "present imperfect," however, we should examine "future perfect."

Population screening in Britain would mean that almost three million people would need to come to terms with carrying a defective gene. Families whose beliefs precluded any interference with procreation would be liable to ostracism; criticism from neighbours might even pressure them into participation. ${ }^{2}$ Most children with cystic fibrosis are fit, and their life expectancy is increasing and may soon be greatly improved by gene therapy. Are we in danger of screening for a genetic disorder that will soon cease to be a disease at all?

Countering these arguments is not difficult. Almost everyone carries a severe recessive gene defect. Previously, population screening for such genes has focused on ethnic minorities ${ }^{3}$ - cystic fibrosis merely extends this concept to the population at large. As the human genome project gathers pace we may anticipate the ability to detect all major recessive genes in the near future. When everyone realises that he or she 